\title{
Self, Script, and Situation: identity in a world of ICTs
}

\author{
Bibi van den Berg \\ Erasmus University, Faculty of Philosophy \\ Room H5-13, P.O. Box 1738 \\ 3000 DR Rotterdam, The Netherlands \\ vandenberg@fwb.eur.nl
}

\begin{abstract}
In this paper I will elucidate why 'situation' is a constructive unit of analysis for the study of both identity and the impact of technologies (particularly ICTs) on identity. Further, I will use a situational perspective to show some of the ways in which the 'definition of situations' may be affected by such technologies. I will conduct a conceptual analysis of the 'definition of a situation', looking into the notion of 'scripts', to show how alterations in scripts lead to changes in the 'definition of the situation', and these in turn lead to shift in the development and expression of identity.
\end{abstract}

\section{Introduction}

There are many ways of approaching the study of human identity. One of them is to focus on the relationship between human interaction and identity. This approach has been used by symbolic interactionists such as George Herbert Mead [14], and Erving Goffman [9]. In The presentation of self in everyday life [9] Goffman develops what has come to be known as the 'dramaturgy metaphor' [11] or the 'dramaturgical perspective' [4]. In search of an answer to the question 'what is identity?' Goffman turns to everyday, small-scale social engagements between people. His point of departure is the idea that the complex question of what identity is, is best tackled by studying its expression and formation in concrete micro-social interactions between people. For Goffman, identity literally comes about in and through social interactions - it is the 'dramatic effect' of such interactions [4, 9]. In the eyes of Goffman, identity is simply the sum of all the roles we play in our lives. Thus, identity is not some innate quality, nor a physically localizable property. Also, identity is not an essence in itself. Rather, Goffman views identity as the socially constructed result of all our engagements with others.

Goffman's central thesis is that when people engage in social interactions with one another, they conduct 'performances' - they assume a 'role' and try to create as favorable an 'impression' as possible [9]. He argues that identity is the "...result of publicly validated performances." [4]. There is a distinction between the roles people play when they are in a 'front region', i.e. before an audience, and the way they

Please use the following format when citing this chapter:

van den Berg, B., 2008, in IFIP International Federation for Information Processing, Volume 262; The Future of Identity in the Information Society; Simone Fischer-Hübner, Penny Duquenoy, Albin Zuccato, Leonardo Martucci; (Boston: Springer), pp. 63-76. 
behave when they are in a 'back region' or 'backstage', i.e. in spaces where no one is watching them, e.g. within the privacy of their home environment. In such back regions they can rehearse for future performances, rest, relax and let their 'mask' down [9].

\section{Goffman on situations}

But how do people come to choose what 'role' to play when interacting with others? How do they know what behaviors to display when placed in a given situation? According to Goffman people entering a social interaction make use of a 'definition of the situation', a concept that dates back to the American sociologist William Isaac Thomas [21]. A 'definition of the situation' emerges when people - in the words of Joshua Meyrowitz - "ask themselves: "what is going on here?" [16, 17]. The 'answer' a person will come up with forms the basis for the particular action pattern, chosen from a whole range of possible action patterns, he or she will adopt within that setting. Thus, people use the 'definition of the situation' to ascribe meaning to the situation at large and give and interpretation of their specific part to play (i.e. their 'role') within that situation.

It is important to observe that using a 'definition of the situation' is not (necessarily) a rational, conscious process. More often than not, 'answering' the question 'what is going on here?' is not done in an explicit, analytical or logical way, but rather in an immediate, automatic, implicit, un- or pre-conscious manner. The 'answer' to the question becomes visible in the choice of a role and its accompanying actions, but emerges in such an instantaneous, automatic way that the agent oftentimes won't even be aware of the fact that he or she is using a 'definition of the situation' at all to assume a role within the given context. The 'definition of the situation', one could argue, comes about by using what Bourdieu calls 'practical knowledge', which he describes as "...based on the continuous decoding of the perceived-but not consciously noticed..." [3] $]^{1}$.

How people come to define a situation exactly is the topic of the next paragraphs. One preliminary point to be made here is that the definition of the situation always comes about in the interplay between individual interpretations and socialized, internalized cultural meanings. They are the result of two components: on the one hand they stem from the learnt and internalized definitions a person has come to incorporate throughout his upbringing and the socialization processes that continue throughout his life. On the other hand they depend in part on the spontaneous individual interpretation of the current setting by a unique agent, incorporating his or her past experiences and definitions. This explains why individual differences in the 'definition of the situation' may exist.

\footnotetext{
'Although Bourdieu cannot be labeled a symbolic interactionist, he worked on many of the same themes as symbolic interactionists. It is clear from his writings also that he found great inspiration in Goffman's work. See also: [10].
} 
By approaching identity as the performance of different roles in different situations Goffman achieves two goals. Firstly, it enables him to accommodate for the fact that people display different 'sides of themselves' under different circumstances. Secondly, by looking into identity as it is developed, experienced, and expressed in different settings, Goffman can make the notion of 'situations' into the central unit of analysis of his research. Thus, he can analyze, compare and differentiate aspects of identity across different settings, places and times - 'situation' is used as the entity of investigation into which the complexity of social life is dissected. This is why Goffman has been labeled the "quintessential sociologist of the 'situation"" [11].

However, a burning question at the heart of Goffman's line of thinking remains: how does the person come to a 'definition of the situation' in the way he or she does? What 'cues' does he or she use to interpret 'what is going on'? Goffman's theory starts from the assumption that people use definitions in each situation they enter, but does not explain what such definitions are based on. I argue that it is useful to explicate the 'cues' people use to define what the situation is, because by explaining the elements that have an impact on such a definition, it becomes possible to analyze whether fundamental changes in the environments we live and work in, such as the advent of information and communication technologies, will have an impact on the way we define situations and, if so, what form and shape that impact will take. Therefore, we will now turn to Goffman's starting point, the 'definition of the situation', and see if we can clarify the mechanisms at work in the construction of such a definition.

\section{Scripts and situations}

When entering a situation a person uses a 'definition' to establish 'what is going on'. But how does a person come to such a 'definition'? Which elements in the environment, be they physical or social in nature, play a part in the ascription of meaning that arises in this manner?

I argue that each situation contains 'scripts' that human beings use to come to a 'definition of the situation'. I define a script as a set of 'contextual cues' explicitly or implicitly governing (courses of) action in connection with a situation ${ }^{2}$. Scripts provide an indication of the range of appropriate behaviors that apply in the situation. They allow us to quickly distill 'what is going on' and what roles we may choose from, thus allowing us "to do less processing and wondering about frequently experienced events" [20]. My definition of scripts deviates from the meaning ascribed to the same term within the field of Science and Technology Studies (S\&TS). To show in which ways my own definition differs from the one used in S\&TS we will look into their use of this term first.

${ }^{2}$ A situation, in turn, can be defined as an ensemble of a specific meaningful locale (place), and a specific moment in time in which agents, their behaviors, and scripts come together to create a single 'slice of social reality'. 


\subsection{Scripts in Science and Technology Studies}

In S\&TS much research has been conducted regarding the images of and presuppositions concerning 'users' and 'use' that become incorporated into technological artifacts during the design process $[1,2,7,12,18,19]$. In 'script analysis' the term 'script' denotes all the ideas concerning prospected users and practices that are embedded in technological artifacts. Researchers in ST\&S have shown convincingly that such scripts abound in even the most simple and straightforward technological artifacts. For example, Van Oost conducted research on 'gender scripts' and focused on electric shavers developed by Philips Electronics [18]. She found that there are significant differences in the way female and male shavers are designed and marketed - differences expressing conceptions of gender in the minds of the designers. The scripts that are thus embedded in the shavers, Van Oost points out, reify gendered behavioral distinctions. She concludes that "...Philips not only produces shavers but also gender." [18]

A second example of script research in S\&TS is that conducted by Gjøen and Hård on the electric car (EV) and its use and social acceptance in Norway [7]. Gjøen and Hård show that, besides the scripts embedded in the electric car by its designers, users sometimes add their own scripts ('user scripts') to an artifact. One of the users, named Sylvia, created her own script by naming the car 'Barbie' (because it is small and cute). With this feminine name, Gjøen and Hård argue, Sylvia turns existing cultural scripts concerning cars, labeling them as gendered, masculine vehicles, upside down.

\subsection{An alternative approach to scripts}

As these examples show research in Science and Technology Studies predominantly focuses on (a) the design and development process of technological artifacts, and (b) the scripts that are embedded in singular technological artifacts, as opposed to the multitude and variety of scripts that may be present in contexts or environments (of which technological artifacts may be part). Although this approach is valuable for studying the ways in which human-technology interaction is shaped regarding individual artifacts, my use of the notion of 'scripts' broadens the perspective to accommodate the interactions users may have with the milieus they find themselves in. In contradistinction with the approach used in S\&TS I focus on what happens once technological artifacts enter our everyday environments, particularly looking into their 'scriptal influence' in concert with other objects and influences present in a given situation. From this point on, we will therefore see scripts as elements of everyday situations, operating as a variety of 'signs' that together give off suggestions for the ascription of meaning pertaining to 'what is going on' in that situation. 


\section{Script characteristics}

Let us explore the meaning of the notion of 'scripts' as proposed here. From my definition of 'scripts' as 'contextual cues' it follows that they are bound up with the environments or situations that we find ourselves in or move between. Scripts may be present explicitly within a given situation, and thus guide behaviors in a conscious manner, for example when a sign in the park says we are not allowed to walk on the grass. But scripts often do their work in more implicit and unconscious ways. A railway platform with an escalator and staircases leading to the main entrance of the building has implicit scripts concerning the way the flow of passengers should move from the train to the main hall and vice versa. When entering the office building in which one works, there are implicit scripts that guide us in adjusting to the environment, not just in a literal way (we enter the offices in the building through the door and not through one of the windows; we sit on chairs, not on top of our desks), but also in more symbolic ways - we instantly, automatically, and without conscious awareness assume roles appropriate for interactions with colleagues, clients, and superiors, instead of roles we would play in front of friends, spouses or family members. The scripts contained in the environment help us make these transitions from one situation to the next.

Scripts arise on the basis of shared cultural meanings. They are the result of processes of cultural dynamism, in which people create ways of interacting, rules of conduct, legal prescriptions, and so on and so forth to facilitate the relations among participants in social connections and exchanges. Most of these processes of cultural dynamism have been ingrained in our interaction patterns through gradual and unconscious socialization and have been integrated into our repertoire of roles in such a way that we cannot view our exchanges with others apart from them. Meeting and interacting with the world and the other people in it presupposes shared cultural meanings, and precisely these are expressed in the 'cues' we take from the situations we enter: scripts.

Scripts, then, are social constructs. They are created and preserved in and through social processes. Scripts can only be sustained by their affirmation in everyday practices. Goffman calls such affirmations 'everyday-life interaction rituals' [4]. Such rituals consist of all kinds of "...unspoken social traffic rules that pervade everyday existence" [4]. To Goffman, the 'social order' is simply the totality of all of the interaction rituals of a group or culture [8].

Scripts are not arbitrary or without obligations. They call forth a certain level of engagement with the particular situation and create a framework within which a person may choose his or her course of action, so to speak. Also, one could argue that scripts structure situations, in the sense that they provide guidelines for choosing a role befitting the environment a person has entered. 'Scriptal cues' enable us to pick a course of action that is deemed 'appropriate' within the situation. At the same time, however, their structuring capacities are not exhaustive, in the sense that there is room for variation in interpretation and, therefore, room for maneuvering through social traffic with unique personal patterns and courses of actions. Scripts leave room for interpretation, so that the same scripts may not give rise to the same responses in 
different people - on the one hand because every person brings a different set of previous experiences to his interpretation of the situation, which affect the way he or she will 'read' the current one, and on the other hand because every situation is in fact a new one, which means that persons always need to 'improvise' to some extent within the given circumstances. Scripts are non-determinate in this sense. They could be labeled as 'strategy-generating principles', to use a term by Bourdieu [3], principles that accompany people's actions within given situations, but don't determine these actions completely. As Van Oost argues with regards to the scripts embedded in technological artifacts: "Obviously, scripts cannot determine the behavior of users, their attribution of meaning or the way they use the object to construct their identity, as this would lead to the pitfall of technological determinism. Users don't have to accept the script, it is possible for them to reject of adapt it. [...] ...but scripts surely act invitingly and/or inhibitingly..." [18]

As guidelines in action one could argue that scripts condition us to some degree within the situations we enter, since they point us in clear directions. Thus, one might argue, scripts have a repressive effect on our action patterns. They can be seen as expressions of political/power strategies used by some (viz. those in power) to control the behavior of others (viz. those without power). Simultaneously, though, scripts can be conceived of as aides or guidelines that facilitate the burden of having to choose a role in every given situation. Scripts help us select a course of action from a whole range of possible options. So while scripts may indeed be labeled as restrictive, they can also be viewed as supportive, assisting mechanisms. Scripts, therefore, can be said to be both limiting and enabling.

Another characteristic of scripts is that they are interactional mechanisms emerging in a situation. A script is not something that is simply embedded in the environment as a rule etched in stone, to be interpreted and used by every passer-by in the same exact way. Rather, as argued above, scripts leave room for interpretation they are taken to mean one thing by one individual and may be taken to mean something else by someone else. One could argue that the script even comes about only in being a cue for whomever sees its meaning, for whomever takes it to be a cue. This is where my perspective of scripts diverges from that of Roger Schank and Robert Abelson [20]. In Scripts, plans, goals and understanding Schank and Abelson attempt to uncover some of the structures of human knowledge in order to use the outcomes to further research in Artificial Intelligence. Schank and Abelson introduce the notion of a script, which they define as "a predetermined, stereotyped sequence of actions that defines a well-known situation." [20] A script, for them, is a form of 'specialized knowlegde' that allows people to quickly determine what is going on in a specific situation and choose a pattern of action appropriate within the limits of that situation. Schank and Abelson's definition of scripts strongly resembles my own approach - we fully agree on the role scripts play in everyday life (i.e. "scripts handle stylized everyday situations" [20]) and the way in which they are used (i.e. facilitating answering the question 'what is going on here?'). However, whereas Schank and Abelson view scripts as knowledge structures, thereby placing them in the human mind, in my perspective scripts are emergent properties of situations, which come 
about in the interaction between an agent and the situations he enters. Scripts are not elements of the human episteme, but rather situational components.

\section{Script forms and functions}

Scripts come in different forms and fulfill different functions. Most of our everyday interactions are governed by a host of implicit social scripts. Some scripts, though, have been made more explicit and formal - these are expressed, for example, in the legal rules that groups and societies create. In case of an offence such formalized legal scripts are often backed by institutionalized fines or penalties. Unspoken, implicit social scripts lack such official penalties, but violating them may still have severe social implications: crossing the boundaries of what is deemed 'socially appropriate' within a group or culture may result in breaking taboos, which in turn can lead to the social exclusion or shunning of the perpetrator by that social group. Such ostracizing behaviors may last a short time, but can also be of a more permanent nature, depending on the seriousness of the breach caused by the doer, and also on the amount and type of 'repair work' [5] the perpetrator may do.

Then there are scripts that have a physical expression in the environment of the situation. Doors, walls, windows, and traffic lanes are simple examples thereof. Such scripts guide our actions (e.g. entering or leaving a room, driving on the right side of a road) through their material form - they enable certain action patterns, while disabling others. Physical script cues may be conveyed in the space and size of rooms, in the placement of doors and windows, in the ways in which movement is affected through for example the position of barriers and the arrangement of furniture and other physical objects within a spatial plan.

In some cases such materialized scripts have a moralizing property. In his brilliantly funny and insightful article entitled Where are the missing masses? The sociology of a few mundane artifacts [12] Bruno Latour uses the example of seat belts in a car to explicate this point. In some cars, Latour states, the seat belt is connected to the door and gently buckles the driver up automatically once he closes the door. In this type of car the driver cannot choose to not buckle up - the responsibility for buckling up has been removed from the user and delegated to the artifact. Thus, the scriptal influence of the seat belt is absolute.

In most cases, though, the script cues expressed in physical form are not absolute. Entering a room through the door is not as binding a script as the seat belt example described above - we may choose instead to enter through a window (provided there is one), but usually refrain from doing so for reasons of practicality on the one hand, and for reasons social suspiciousness on the other. So although we generally follow the physical script prescribed to us by the shape and placement of a door (e.g. use this hole in the wall to enter or leave a room) this type of script leaves room for maneuvering. 
Broadly speaking, one could say that scripts bring about the emplacement of social regulations, legal rules, political prescriptions, symbolic formulations etc. ${ }^{3}$ However, making a clear distinction between the social, legal, physical, political and symbolic aspects of scripts that may be present in situations is impossible. In the reality of everyday situations different constellations of scripts may be present, working in concert and reinforcing (or combating) one another. It is impossible to untangle these assemblages.

\section{Adding technologies to situations}

The next question to be addressed is: what is the impact of the addition of technologies (in particular ICTs) to existing situations? In which ways does the addition of such technologies to existing situations affect the scripts in that situation and, in turn, the 'definitions of situations'?

Before looking into the changes brought about in the 'definitions of situations' by the advent of new technologies, we need to establish what kind of situational changes technologies cause: do they interfere with situations on a script level, e.g. do they create new situational action cues within given contexts? Or are they rather physical and informational additions to the environment that may affect existing scripts but do not function as such themselves? In order to answer this question I would like to use Roger Silverstone's notion of 'double articulation'. According to Silverstone technologies always have 'double articulation': they are both "material objects located in particular spatio-temporal settings" and "symbolic messages located within the flows of particular socio-cultural discourses" [13]. Thus, communication technologies have both a material expression, they are objects like any other, but at the same time they enable communication with and information regarding the outside

${ }^{3}$ Scripts show a certain amount of overlap with what in common sense language we call 'rules'. An extensive field of study has developed in a wide range of scientific fields, ranging from philosophy, to Artificial Intelligence, and to law, as to what the precise nature of 'rules' and 'rule-following' is. The common sense meaning of a 'rule' refers to either explicit (and even codified) instructions with regard to the fulfillment of actions, or explicit (and even codified) instructions with regard to the limitations of actions. Comparing this notion of rules to my conception of scripts, one could argue that rules are declarative (i.e. they refer to a correlation between a specific state of affairs and an action pattern to be taken), scripts are more procedural in nature: they refer to implicit or tacit knowledge that we may use within a contextual frame of reference. However, within modern philosophy an extended debate between such prominent scholars as Wittgenstein, Ryle, and Searle, has led to a different perspective on 'rule-following'. In this conception 'rule-following' refers to socially constructed, contextual, and (most importantly) rather implicit knowledge which is adopted in specific instances. Within this debate 'rules' are highly similar in meaning as 'scripts'. Solving this conceptual confusion unfortunately falls far outside the limits of this paper. We will leave the issue by concluding that both 'rules' and 'scripts' are complex, diffuse concepts, whose precise definition and demarcation, both separately and in relation to each other, deserves further attention in a separate paper. 
world to enter the domestic environment. When translated to the current problem at hand, one could say that they function both as objects in a situation, and as situational scripts.

Thus, technologies have the ability to change situations, either as script forces, or as situational elements. But how does this happen precisely? I argue that there are four ways in which technologies have a bearing on the 'definition of the situation'.

\subsection{Boundedness}

First of all, the presence of ICTs alters the boundedness of situations, as Joshua Meyrowitz argues [15-17]. Electronic media have an impact on the permeability of a situation's boundaries. Whereas situations traditionally may be said to link up with bounded, physical places, electronic media break through this boundedness, and even dissolve it [17]. Meyrowitz writes: "The pre-electronic locality was characterized by its physical and experiential boundedness. Situations were defined by where and when they took place and by who was physically present - as well as by where and when they were not taking place and by who was not physically present at particular events. [...] Now such boundedness requires some effort: Turn off the mobile phones, PDAs, and laptops; banish radio and television. [...] In most settings in a post-modern society [...] the definitions of the situation are multiple and unstable, able to shift with the ring or buzz of a telephone or with the announcement of a 'breaking story" [17] And Meyrowitz concludes: "By changing the boundaries of social situations, electronic media do not simply give us quicker or more thorough access to events and behaviors. They give us, instead, new events and new behaviors." [16]

According to Meyrowitz, the advent of electronic media leads to the destabilization of the 'definitions of situations' since we are 'always connected' through such media. This means that our 'definition of the situation' may change the instant the phone rings or an email is received on the PDA. Whereas only a few decades ago physical seclusion meant social seclusion as well, in the days of mobile and ubiquitous computing this is no longer the case.

Meyrowitz compares electronic media to traditional ones, like books and clay tablets. He points out that print media always had to be moved physically from place to place and usually traveled with the person who owned them, at the speed of human travel [16]. Electronic media have changed all of this. Whereas in the pre-electronic age the amount of information that entered or left a situation was bound up with rules of access for (groups of) people on the one hand and with physical carriers, such as books, papyrus roles, or clay tablets on the other, electronic media have dissolved this link. Walls, doors and fences are of no consequence in the social insulation of a place that is electronically mediated. The physical transportation of messages and communications in the digital age is infinitely faster than that of the human traveler (and becoming faster every day), and digital media have no need for material carriers, such as books or scrolls, nor do they depend on human beings literally bringing them from one location to the next. All of this has enhanced easy access for electronic media and their contents to situations and localities. 


\subsection{Physical place and social place}

Second of all, the spread of technologies has lead to the disconnection of "physical place' and 'social place'. This point, too, derives from Meyrowitz's No sense of place. Before the age of electronic media, he argues, 'physical place' and 'social place' coincided: in order to have specific social interactions, one had to go to specific physical places. Access to and presence in these physical places enabled certain social interactions, whereas those who did not have access or were not present in them were excluded from participating in the interaction. Let me illustrate this with an example. In the past, members of an exclusive 'Gentlemen's Society' would visit meetings with other members ('social place') at a specific physical location, viz. the society's Club House ('physical place'). Non-members did not have access to this physical place, and therefore had no access to the 'social place' of a Gentlemen's Society. Electronic media, Meyrowitz argues, have had a profound impact on situations such as these. Non-members of a distinguished club may now gather information about what it means to be in such a club by browsing the club's website or perhaps by viewing a documentary about it on television.

Of course, there is still a lot of social information that is actually closely tied to specific physical place - the uncoupling of 'physical place' and 'social place' has not made 'physical place' completely irrelevant as a category of experience, nor do we have access to any and all physical places, simply because we may be able to gain access to (a wide variety of) social places. Rather, Meyrowitz's point is that the connection between 'physical place' and 'social place', which was complete in preelectronic times, has been greatly weakened ever since the introduction of electronic media.

Since information and communication technologies have come to pervade physical settings at any given moment and thus have turned literally physical places into technologically mediated ones, this has a bearing on the 'definition of the situation': 'what is going on' is no longer strictly bound up with the physical place one finds oneself in; a person can be physically present in one place, and yet be 'socially' absent from it, for example because he or she is on the phone talking to someone who is not physically present - this person thus really 'is' somewhere else entirely. Kenneth Gergen calls this notion 'absent presence', being somewhere, yet not being there at the same time [6]. Gergen writes: "One is physically present but is absorbed in a technologically mediated world elsewhere. Typically it is a world of relationships, both active and vicarious, within which domains of meaning are being created or sustained. Increasingly, these domains of alterior meaning insinuate themselves into the world of full presence - the world in which one is otherwise absorbed and constituted by the immediacy of concrete, face-to-face relationships." [6]

This means that there is a decreased relevance of our physical presence in situations. 'Being present' in a situation literally is no longer related to one's physical location, but has rather become an informational property: being 'present' means being 'tuned-in'. Note once more, that because of the disconnection between physical and social place the 'definition of the situation' has become more instable: it can 
change in the blink of an eye as a result of the 'social interference' that electronic media may cause. As we have seen above, a situation that was defined as one type of setting by its participants may change instantly as a result of a technological artifact's 'intrusion'.

\subsection{Middle region behaviors}

A third point, again put forth by Meyrowitz, refers to Goffman's distinction between 'front region' behaviors and 'back region' behaviors [9]. As stated at the beginning of this article, Goffman points out that people play out 'performances' when they are in front of an audience, for which they want to create a favorable 'impression'. Such performances are labeled as 'front region behaviors'. When there is no audience present individuals (or teams of players) can relax, let down their guard, and rehearse for future performances. Goffman calls this 'back region behavior'. With the advent of electronic media, Meyrowitz argues, the clear distinction between 'front region' and 'back region' as separate regions, each with their own repertoire of behaviors, starts to crumble [16]. He concludes that the merging of front region and back region behaviors leads to a host of new behavioral practices, which he labels as 'middle region behaviors': "In middle region behaviors, the extremes of the former front region are lost because performers no longer have the necessary backstage time and space; the control over rehearsals and relaxations that supported the old front region role is weakened. The new behaviors also often lack the extremes of the former backstage behavior because the new middle region dramas are public (that is, performed before an (audience') and, therefore, performers adapt as much as possible to the presence of the audience, but continue to hide whatever can still be hidden." [16]

Meyrowitz has an ecological conception of situations and the behaviors we may find in them. He argues that when formerly separate situations merge, this does not result simply in the combination of both of these formerly disconnected situations, but rather in a new merged situation, with new behavior patterns.

Electronic media, Meyrowitz argues, may also give rise to the merging of formerly separate situations. For example, using a home telephone to conduct workrelated business opens the private 'back region' of the home temporarily into a 'front region'. Similarly, displaying 'private' ('back region') behaviors on television in front of a large audience turns them into 'front region behaviors'. Also, television, the internet and other ICTs allow formerly distinct social groups (divided by age, gender, etc.) to gather information about each other. This, Meyrowitz suggests, leads to homogenization of knowledge, in the sense that more people have access to the same types and contents of information. Again, the emergence of a middle region is the result: since the strict distinction between social groups lessens, new behaviors emerge that correspond to the fusion of these groups and their situations.

Technologies, then, clearly affect the 'definitions of the situation'. Who we are in each situation, and what we show of ourselves, has become more fluid in the current age of information and communication technologies, and all the more so with the 
recent emergence of mobile technologies, that have aided in further destabilizing the boundaries between public and private behaviors.

\subsection{Situational function}

Lastly, I argue that ICTs, particularly mobile technologies, have changed the function of the situations we find ourselves in. As we have seen, Meyrowitz argued that the link between 'physical place' and 'social place' has been weakened by the advent of electronic media. Specific situations, that used to be bound up with particular locations in space and time, such as visiting a movie theater, attending a church service or going to a store, have become uncoupled from their former physical locations (although one can still go to their respective locations to get such experiences) - we can now watch a movie on television or on our iPods, download it from the internet or rent it from a video store; we can watch a church service on television, listen to it over the radio, or download the latest service as a Podcast; and we can shop for virtually anything through catalogues and on the internet. However, it is not just physical and social place that become separated; we may say the same of physical place and spatial function.

In the pre-digital age there was a close connection between a physical place and the function it fulfilled. For example, a train functioned as a public space, which one entered to travel from A to B, a park was a space used to relax and enjoy the weather or the green surroundings, an office was a semi-public space used to work etc. Although physical places could fulfill more than one function, their functions were usually limited in scope. With the advent of information and communication technologies, particularly mobile technologies, some of these limitations were lifted. A park may now function in the same 'traditional' ways, as a meeting place, a place to relax, a place to do exercise etc., but it may also be used as a place to work, using a laptop, a mobile phone, a PDA, or all of these combined. Information that was previously unavailable in the park, such as one's personal computer files or webpages on the internet, are now available in those green surroundings (or basically anywhere, anytime). This means the function a space like a park may fulfill in our everyday lives has expanded: on top of the 'traditional' functions a park had, it may now include a work function, a technologically mediated communication function, a technologically provided entertainment and information function, etc. Thus, the clear tie between physical place and spatial function of the pre-electronic age has weakened.

As a consequence, the clear situational divisions of old days, for example between public and private situations, have become blurred. For example, a train may function as a (semi-) personal space when we use it to have intimate discussions over the phone, and a park may function as (semi-) public one when we sit on a bench to work on a laptop. While such situations were previously seen as either private or public, they now may be both of these at the same time, or one or the other in rapid succession. It is obvious that alterations in the function of places and spaces again leads to a destabilization, or at least an immense expansion of the 'definition of the situation': since the range of possible patterns of action has expanded as a result of 
our being always-on and always-connected through mobile technologies, there is more variation in how we define 'what is going on' in each situation we enter.

\section{Situations, technologies and identity}

In which ways do these four types of destabilization affect human identity? At the beginning of this chapter I argued that we use 'definitions of situations' to come to terms with 'what is going on' in a specific context, to ascribe meaning to that context, and to choose an appropriate course of action, a role, within that context. With Goffman I stated that identity might be viewed as the totality of all of the roles we play throughout our lives. Thus, I argued, the 'definition of the situation' forms the starting point for role choices, and hence for the construction and expression of identity. As we have seen in this chapter, scripts play a fundamental role in establishing 'what is going on' in each situation, and changes in situations or scripts, for example brought about by the addition of information and communication technologies to these situations, have an impact on how we define them.

We may conclude that changes in the 'definition of the situation' have a direct and profound impact on identity. After all, when the 'definitions of the situation' change, role choices and cues are affected, which in turn has an effect on identity. ICTs may function as situational change factors, therefore have a bearing on identity. They affect identity because they change situations, either as situational elements or as scripts, and thus impinge on the 'definitions of the situation' we formulate.

We may conclude that the emergence of information and communication technologies, particularly the more recent development of mobile technologies, has led to a tremendous expansion of the possible definitions we may use to come to grips with role choices in each situation. Since the amount of roles to choose from is destabilized and increased in each specific situation, the bandwidth for choosing stretches as well, thereby creating a double effect: on the one hand individuals get more freedom and flexibility to choose roles in given situations. This means they may choose more freely what they want to do (and in turn, by effect, ultimately who they are). At the same time, however, this places an ever-bigger burden of choice on these individuals. The sum total of all the roles we may play in life is enlarged, thus dramatically expanding the necessity for human beings of merging the vast amount of separate roles they play into some form of a combined self. ICTs thus function both as mechanisms of liberation yet at the same time also helps corrode coherent and simple senses of self. Therefore, it is too simplistic to view the effects of ICTs on situations as 'good' or 'bad' - their complexity calls for a more nuanced analysis.

\section{References}

1. M. Akrich, in: Shaping technology/building society: Studies in sociotechnical change, edited by W.E. Bijker and J. Law (MIT Press, Cambridge, Mass., 1992), 205-224. 
2. M. Akrich, in: Managing technology in society: The approach of constructive technology assessment, edited by A. Rip, T.J. Misa and J. Schot (Pinter Publishers: Distributed in the United States and Canada by St. Martin's Press, London; New York, 1995), 167-184.

3. P. Bourdieu, Outline of a theory of practice (Cambridge University Press, Cambridge, New York, 1977).

4. A. Branaman, in: The Goffman reader, edited by C.C. Lemert and A. Branaman (Blackwell, Cambridge, Mass., 1997), xlv-lxxxii.

5. T. Burns, Erving Goffman (Routledge, London; New York, 1992).

6. K.J. Gergen, in: Perpetual contact: Mobile communication, private talk, public performance, edited by J.E. Katz and M.A. Aakhus (Cambridge University Press, Cambridge, UK; New York, 2002), 227-241.

7. H. Gjøen and M. Hård, Cultural politics in actions: Developing user scripts in relation to the electric vehicle, Science, Technology \& Human Values 27 (2), 262-281 (2002).

8. E. Goffman, Relations in public: Microstudies of the public order (Harper Colophon Books, Harper \& Row Publishers, New York, 1972).

9. E. Goffman, The presentation of self in everyday life (Doubleday, Garden City, N.Y., 1959).

10. R. Jenkins, Social identity (Routledge, London; New York, 2004).

11. O.B. Jensen, 'Facework', flow and the city: Simmel, Goffman, and mobility in the contemporary city, Mobilities 1 (2), 143-165 (2006).

12. B. Latour, in: Shaping technology/building society: Studies in sociotechnical change, edited by W.E. Bijker and J. Law (MIT Press, Cambridge, Mass., 1992), 225-259.

13. S.M. Livingstone, On the material and the symbolic: Silverstone's double articulation of research traditions in new media studies, New Media \& Society 9 (1), 16-24 (2007).

14. G.H. Mead and C.W. Morris, Mind, self \& society from the standpoint of a social behaviorist (The University of Chicago Press, Chicago, Ill., 1934).

15. J. Meyrowitz, in: Mobile democracy: Essays on society, self and politics, edited by $\mathrm{K}$. Nyíri (Passagen Verlag, Vienna, 2003), 91-102.

16. J. Meyrowitz, No sense of place: The impact of electronic media on social behavior (Oxford University Press, New York, 1985).

17. J. Meyrowitz, in: The global and the local in mobile communication, edited by K. Nyíri (Passagen Verlag, Vienna, 2005), 21-30.

18. E.v. Oost, in: How users matter: the co-construction of users and technologies, edited by N. Oudshoorn and T. Pinch (MIT Press, Cambridge, Mass., 2003), 193-209.

19. N. Oudshoorn and T.J. Pinch, How users matter: The co-construction of users and technologies (MIT Press, Cambridge, Mass., 2003).

20. R.C. Schank and R.P. Abelson, Scripts, plans, goals, and understanding: An inquiry into human knowledge structures (L. Erlbaum Associates; distributed by the Halsted Press Division of John Wiley and Sons, Hillsdale, N.J. New York, 1977).

21. W.I. Thomas and M. Janowitz, W. I. Thomas on social organization and social personality: Selected papers (University of Chicago Press, Chicago, 1966). 